\title{
A comparative study of Endoscopic versus Navigation guided microscopic transsphenoidal pituitary surgery at Tertiary care Centre in India
}

\author{
Anurag Sahu ${ }^{1}$, Sharad Pandey ${ }^{2}$, Kulwant Singh ${ }^{1}$, Vivek Sharma ${ }^{1}$ \\ ${ }^{1}$ Department of Neurosurgery, Sir Sunder Lal Hospital, IMS, BHU, Varanasi, INDIA \\ ${ }^{2}$ Department of Neurosurgery, P.G.I.M.E.R. Dr. Ram Manohar Lohia Hospital, New Delhi, INDIA
}

\begin{abstract}
Introduction: The transsphenoidal route for pituitary surgery is considered the standard treatment for pituitary adenomas. The disadvantage of the smaller exposure of this route is partially compensated for by the introduction of the microscope with its coaxial illumination, stereoscopic view, adequate magnification, and microsurgical instruments. However, there are only few reports about the outcome of endonasal endoscopic transphenoidal technique. Aims \& Objectives: Current study has been conducted to compare the efficacy, advantages and dis advantages of endoscopic versus navigation guided microscopic transsphenoidal Pituitary surgery. Material and methods: A controlled study was done in the department of neurosurgery, at tertiary care hospital in India, from the period of August 2012 to December 2017 prospectively. In Group A30 patients in whom endoscopic transnasal trans Sphenoidal pituitary surgery and in Group B - 30 patients, intraoperative neuronavigation was used. Observations and Results: Both the groups were similar in demographic variables. The most common age group of pituitary tumor patients was 30-40 years. Fourteen (46.6\%) patients in group A and fifteen ( $50 \%$ ) of the patients in group B had tumor volume less than $5 \mathrm{ml}$. In group A, thirteen (43\%) patients had intrasellar tumors with no suprasellar extension, while in group B, fifteen (50\%) patients had intrasellar tumors with no extension. Operative time was noted from incision to closure and average time taken in both the groups was compared. Twenty five (83\%) cases of group A took between 2-3 hours and only four cases $(13 \%)$ took more than 3 hours. While in group B, twenty $(66 \%)$ cases took between 4-5 hours. This shows a significant difference by fisher extact test $(\mathrm{p}<0.001)$ in the operative time required in both the groups. Eighteen (60\%) patients in group B had a residual volume between 1-1.5 ml while only two patients in group A had so. This difference is also significant Fischer Exact test $(\mathrm{p}<0.001)$. Four $(13.3 \%)$ patients in group A had diabites insipidus while only half of this, i.e. two (6.6\%) had so in group B. however
\end{abstract}


this difference in postoperative complication rate is not statistically significant between two groups. Conclusion: The results of our study correlate with many previous studies to compare endoscopic and microscopic transsphenoidal surgery. These two approaches are equally efficacious in oncological outcomes and the complication rates are comparable.

Key words: endoscopic transphenoidal, navigation guided, Pituitary surgery

\section{Introduction}

The transsphenoidal route for pituitary surgery, via either sublabial or septal incisions, is now considered the standard treatment for pituitary adenomas [13]. Its main advantage lies in its safety. The midline access avoids injury to the internal carotid artery and optic nerves. In contrast to the transfrontal approach, the use of the transsphenoidal technique minimizes the risk of brain trauma, with the resultant short and uncomplicated postoperative course. The disadvantage of the smaller exposure of this route is partially compensated for by the introduction of the microscope with its coaxial illumination, stereoscopic view, adequate magnification, and microsurgical instruments. Except for the use of the operating microscope, the transsphenoidal approach advocated and popularized by Hardy [13], has changed little over the years. Resection of the pituitary tumor is then performed under microscopic magnification and intraoperative fluoroscopic imaging [5]. The visualization provided by the operating microscope is also limited by the optical properties of the lens and light source. The success of endoscopic paranasal sinus surgery has aroused the interest in the use of endoscopes during pituitary surgery [5]. Other investigators used the direct endonasal endoscopic transphenoidal technique $[5,4,3$, 29]. However, there are only few reports about the outcome of this technique.

\section{Aims \& Objectives}

Current study has been conducted to compare the efficacy, advantages and dis advantages of endoscopic versus navigation guided microscopic transsphenoidal Pituitary surgery.

\section{Material \& Methods}

A controlled study was done in the department of neurosurgery, at tertiary care hospital in India, from the period of August 2012 to December 2017 prospectively. During this period a total number of 60 patients were enrolled in the study. Radiological support was provided by Department of Radio diagnosis at the institute. The inclusion criteria for the study were as follows:

1. MRI/CT proven pituitary macroadenoma cases

2. Cases of pituitary microadenoma in which medical treatment has failed and have been planned for surgery.

All the patients were admitted in the Neurosurgery wards. Appropriate consent was taken from all the patients.

The patients were randomly divided in two groups:

1. Group A - 30 patients in whom endoscopic transnasal trans Sphenoidal pituitary surgery was done. 
2. Group B - 30 patients, in whom intraoperative neuronavigation was used for localization of sphenoid sinus and sella turcica during transsphenoidal surgery for removal of pituitary tumor.

Pre-operative CT/MRI was done to assess tumor size, different anatomical variations of sinus (degree of pneumatization, sellar configuration and substation pattern) and intercarotid distance.

In group $\mathrm{A}$, pre-operative endoscopic and imaging evaluation of paranasal sinuses and position of nasal septum were noted.

In group B, contrast enhanced CT scan of the patients was taken in Neuronavigation protocol one day prior to surgery. The data was stored in NR CD/DVD in DICOM format and was loaded on Treon plus Stealth Station Medtronic.

Postoperatively, all the patients were shifted to neurosurgical ICU for elective ventilation. They were extubated in the next morning. A postoperative CT Scan (plain and contrast enhanced) of head was done for assessment of residual tumor volume / hematoma in all patients. Endonasal packing was removed after 48 hours and patients were allowed orally. Patients were followed up in the postoperative period for any complication. Patients were discharged after removal of abdominal stitches on seventh post-operative day. Patients were called for follow-up after 2 weeks.

\section{Results and Discussion}

The present study was done in the department of Neurosurgery, from the period of August 2012 to December 2017 prospectively. Demographic characteristics of all patients like age, gender, tumor volume and suprasellar extension of tumor were noted as on Table 1.

Both the groups were similar in demographic variables as shown in the table. The most common age group of pituitary tumor patients was $30-40$ years. There is no significant sex predilection in patients of pituitary tumors.

Fourteen (46.6\%) patients in group A and fifteen $(50 \%)$ of the patients in group B had tumor volume less than $5 \mathrm{ml}$. In group $\mathrm{A}$, thirteen $(43 \%)$ patients had intrasellar tumors with no suprasellar extension, while in group $\mathrm{B}$, fifteen (50\%) patients had intrasellar tumors with no extension. None of the patient in both the groups had intradural or extradural extension into cavernous sinus.

Clinical presentation and operative and postoperative findings of patients were noted as in Table 2. Eleven (36\%) patients in group A and fourteen (46\%) patients in group B presented to the OPD with endocrine syndromes due to hypersecretory tumors. Most common were prolactinomas followed by growth hormone related symptoms. Operative time was noted from incision to closure and average time taken in both the groups was compared. Twenty five (83\%) cases of group A took between 2-3 hours and only four cases (13\%) took more than 3 hours. While in group B, twenty (66\%) cases took between 4-5 hours. Only two (7\%) cases could be completed in less than 4 hours and eight (26\%) cases even took beyond 5 hours. This shows a significant difference by fisher extact test $(p<0.001)$ in the operative time required in both the groups. 
TABLE 1

Demographic Characteristics of patients

\begin{tabular}{|c|c|c|}
\hline & Group A $(\mathbf{n}=30)$ & Group B $(n=30)$ \\
\hline \multicolumn{3}{|l|}{ Sex } \\
\hline Male & 13 & 15 \\
\hline Female & 17 & 15 \\
\hline \multicolumn{3}{|l|}{ Age group } \\
\hline $10-20 \mathrm{yrs}$ & 1 & 1 \\
\hline $20-30$ yrs & 5 & 6 \\
\hline $30-40$ yrs & 21 & 20 \\
\hline $40-50$ yrs & 3 & 3 \\
\hline \multicolumn{3}{|l|}{ Tumor volume (ml) } \\
\hline$<5$ & 14 & 15 \\
\hline $5-10$ & 11 & 10 \\
\hline $10-15$ & 4 & 3 \\
\hline $15-20$ & 1 & 2 \\
\hline Suprasellar extension absent & 13 & 15 \\
\hline Suprasellar extension present & 17 & 15 \\
\hline a. Expanding into suprasellar cistern & 11 & 9 \\
\hline b. Obliteration of anterior recess of third ventricle & 5 & 4 \\
\hline c. Gross displacement of floor of third ventricle & 1 & 2 \\
\hline d. Intradural/ intracranial extension & 0 & 0 \\
\hline Extradural extension(into or beneath cavernous sinus) & 0 & 0 \\
\hline
\end{tabular}


TABLE 2

Clinical presentation and operative and post-operative findings of patients

\begin{tabular}{|c|c|c|c|}
\hline Clinical presentation & Group A & Group B & \\
\hline Endocrine syndromes & 11 & 14 & \\
\hline Prolactin & 6 & 5 & \\
\hline Growth hormone & 4 & 8 & \\
\hline ACTH & 1 & 1 & \\
\hline Mass effect & 17 & 15 & \\
\hline Pituitary apoplexy & 2 & 1 & \\
\hline Operative time & Group A & Group B & \multirow{6}{*}{ p $<0.001$} \\
\hline Up to 2 hours & 1 & 0 & \\
\hline 2-3 hours & 25 & 0 & \\
\hline 3-4 hours & 4 & 2 & \\
\hline 4-5 hours & 0 & 20 & \\
\hline$>5$ hours & 0 & 8 & \\
\hline Intra operative complication & Group A & Group B & \multirow{4}{*}{$\mathrm{p}<0.001$} \\
\hline Hemorrhage & & & \\
\hline$<100 \mathrm{ml}$ & 25 & 5 & \\
\hline$>100 \mathrm{ml}$ & 5 & 25 & \\
\hline CSF leak & 6 & 4 & $\mathrm{p}<0.217$ \\
\hline Residual Tumor volume (ml) & Group A & Group B & \multirow{6}{*}{$\mathrm{p}<0.001$} \\
\hline $0-0.5$ & 20 & 3 & \\
\hline $0.5-1.0$ & 8 & 4 & \\
\hline $1.0-1.5$ & 2 & 18 & \\
\hline $1.5-2.0$ & 0 & 3 & \\
\hline$>2.0$ & 0 & 2 & \\
\hline Post-operative complications & Group A & Group B & \multirow{6}{*}{$p=0.176$} \\
\hline Diabitis insipidus (transient) & 4 & 2 & \\
\hline CSF rhinorrhea & 3 & 3 & \\
\hline Meningitis & 0 & 3 & \\
\hline Vision loss & 0 & 2 & \\
\hline Sinusitis & 1 & 3 & \\
\hline
\end{tabular}




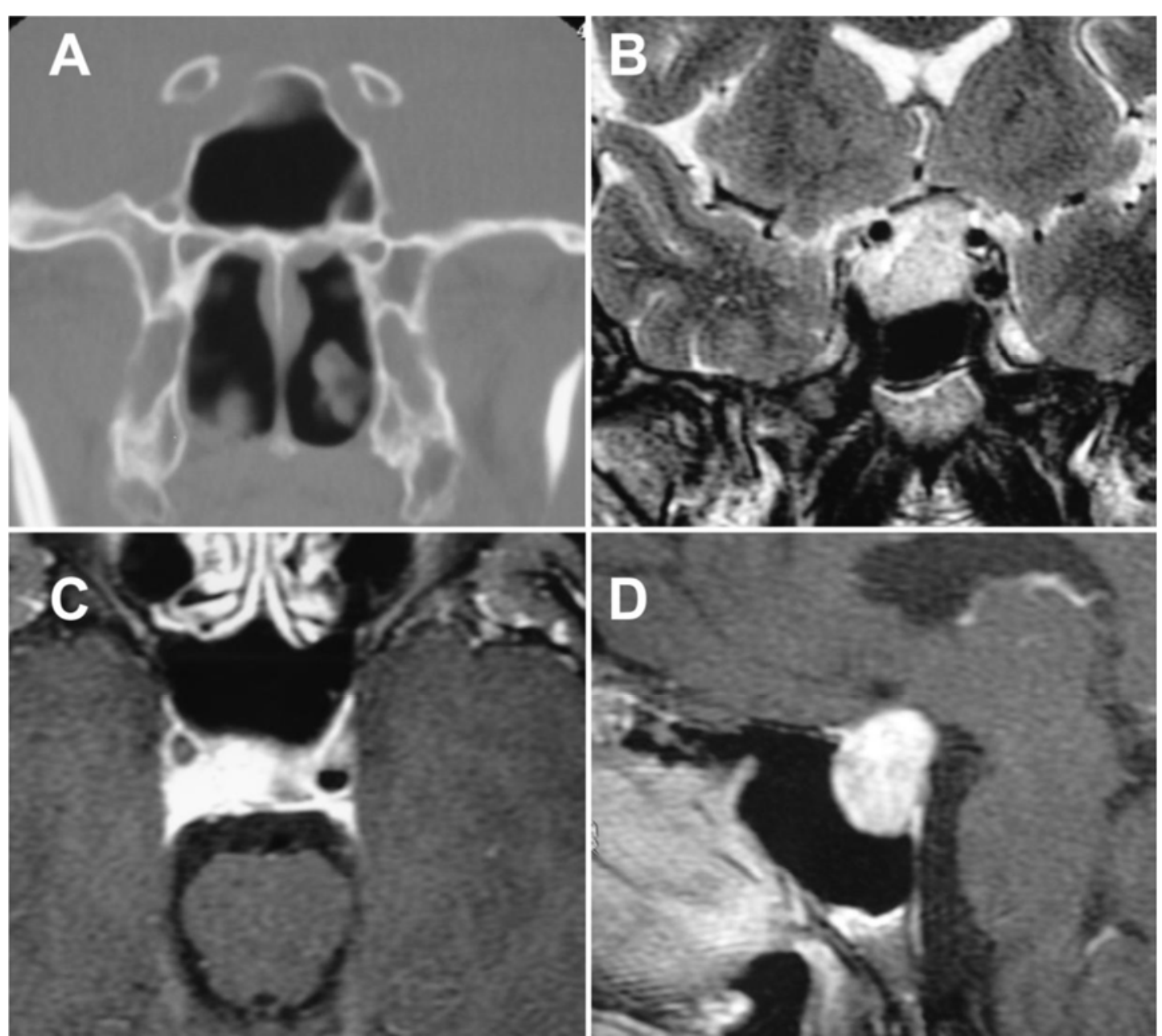

Figure 1 - Imaging studies. A: Coronal computer tomography (CT) image showing the sphenoid sinus. B: Coronal magnetic resonance imaging (MRI) showing the relationship between the pituitary tumor, the internal carotid arteries and the sphenoid sinus. C: Axial MRI to evaluate the lateral extension of the tumor and any involvement of the cavernous sinus. D: Sagittal MRI 


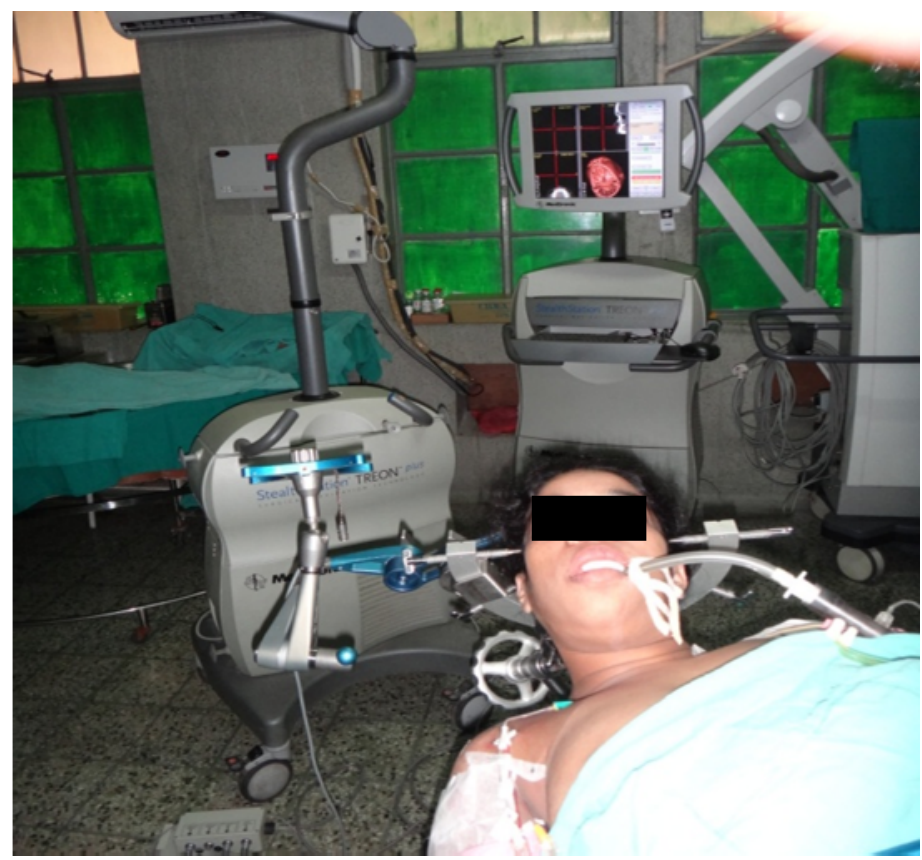

Figure 2 - Patient's head fixed on Sugita head clamp with reference frame attached on supporting arm

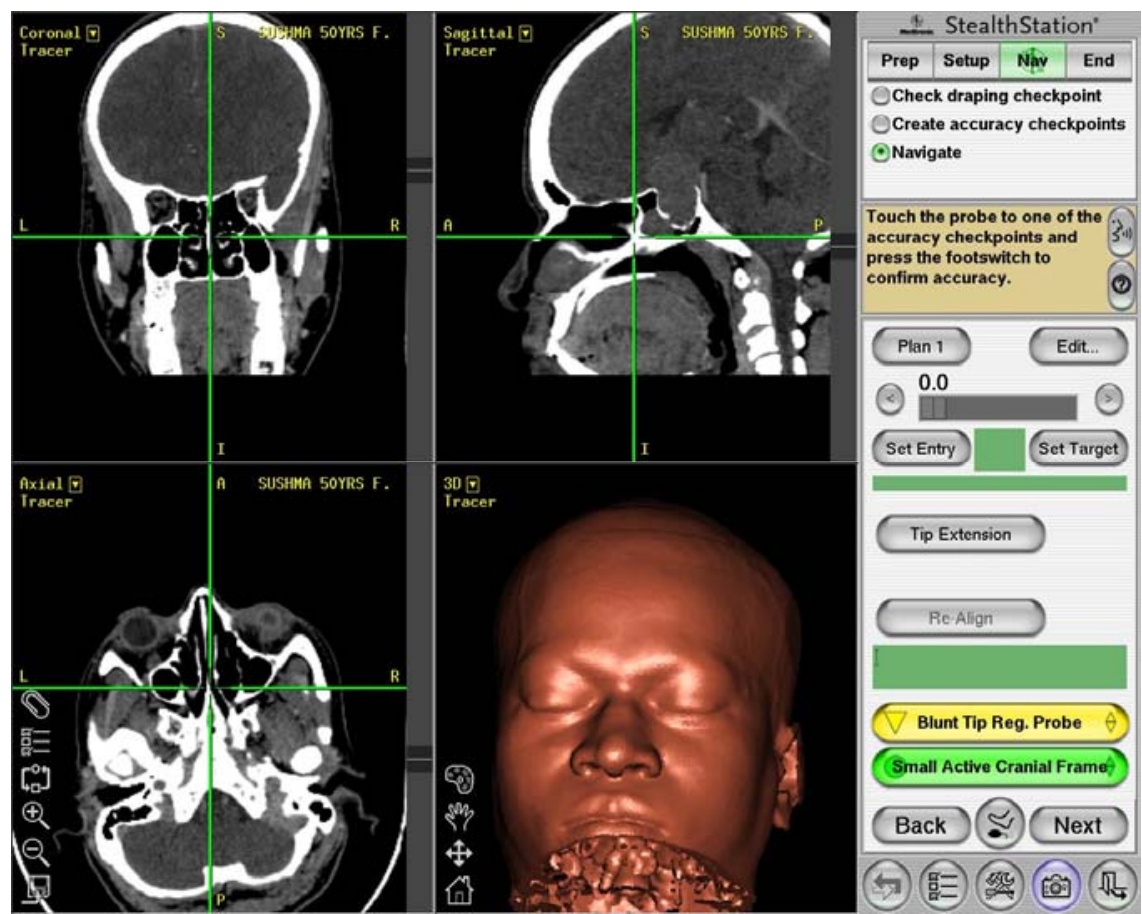

Figure 3 - Photograph showing navigation probe in midline at the floor of sphenoid sinus 
ENDONASAL ENDOSCOPIC VIEW WITH 00 ENDOSCOPE

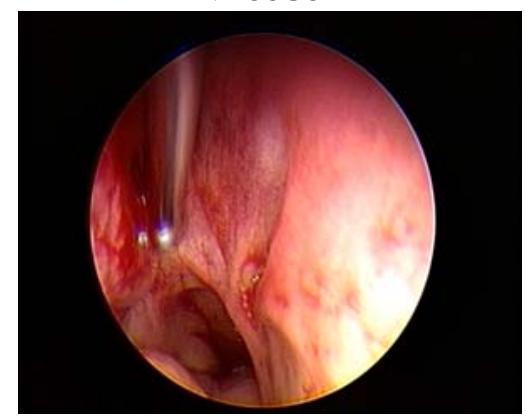

Right Nostril with choana and Turbinate

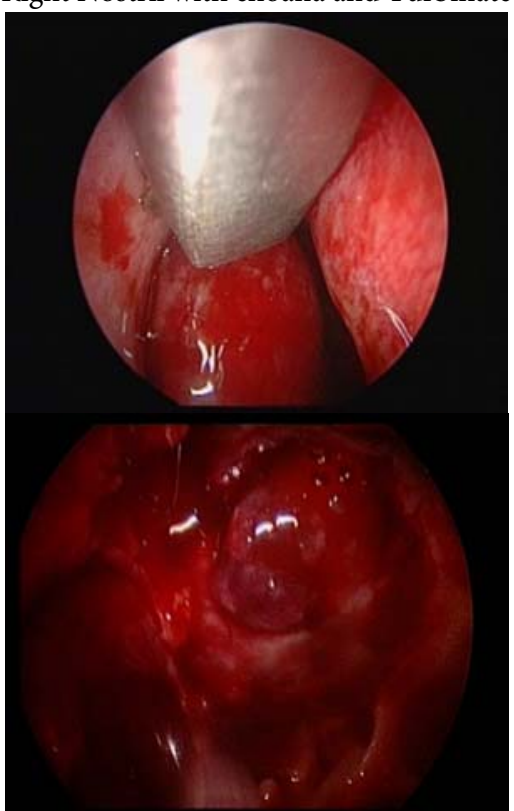

Tumor Removal \& Examination of Sella

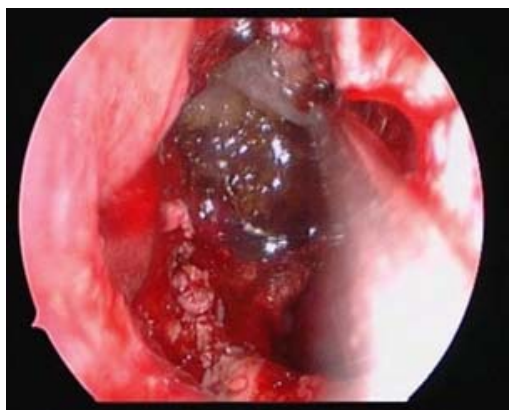

Repair of the Sellar Floor with Abdominal Fat \& fibrin Glue
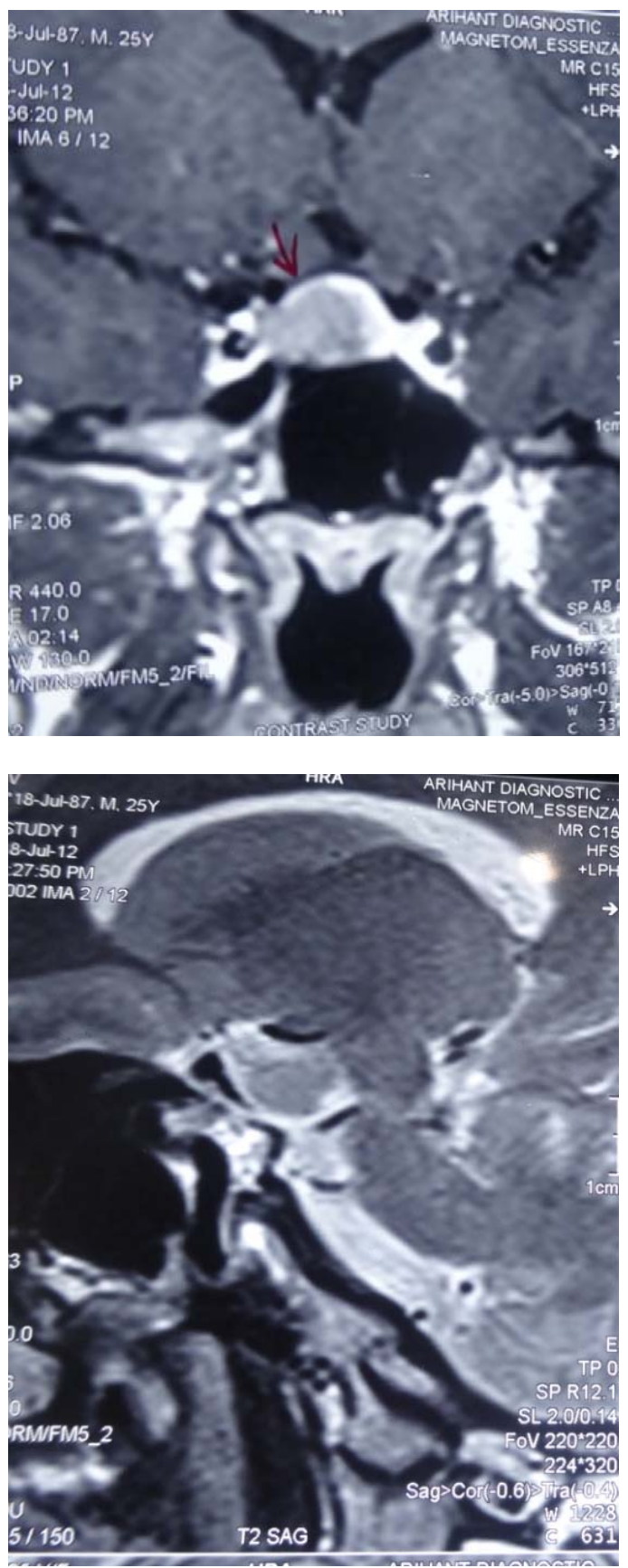

Pre-Operative MRI Images Coronal \& Sagittal Sections Showing Pituitary Macroadenoma 

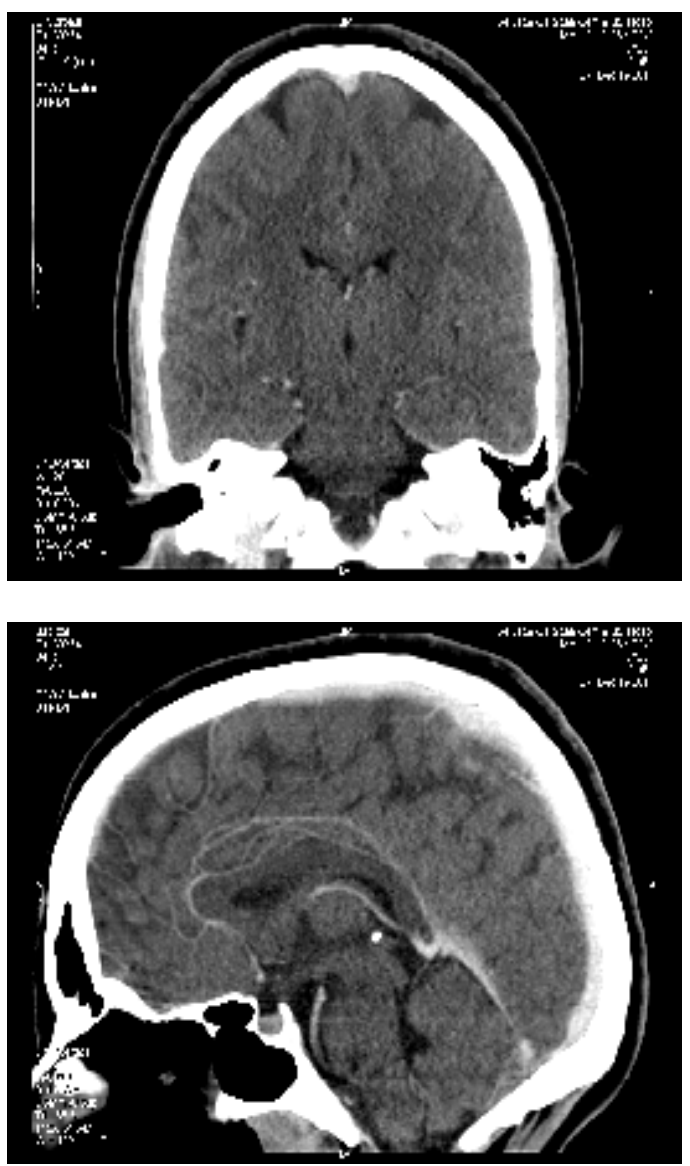

Post-Operative CT Scan Images Coronal \& Sagittal Sections Showing Complete Tumor Resection with Enhancing Normal Pituitary
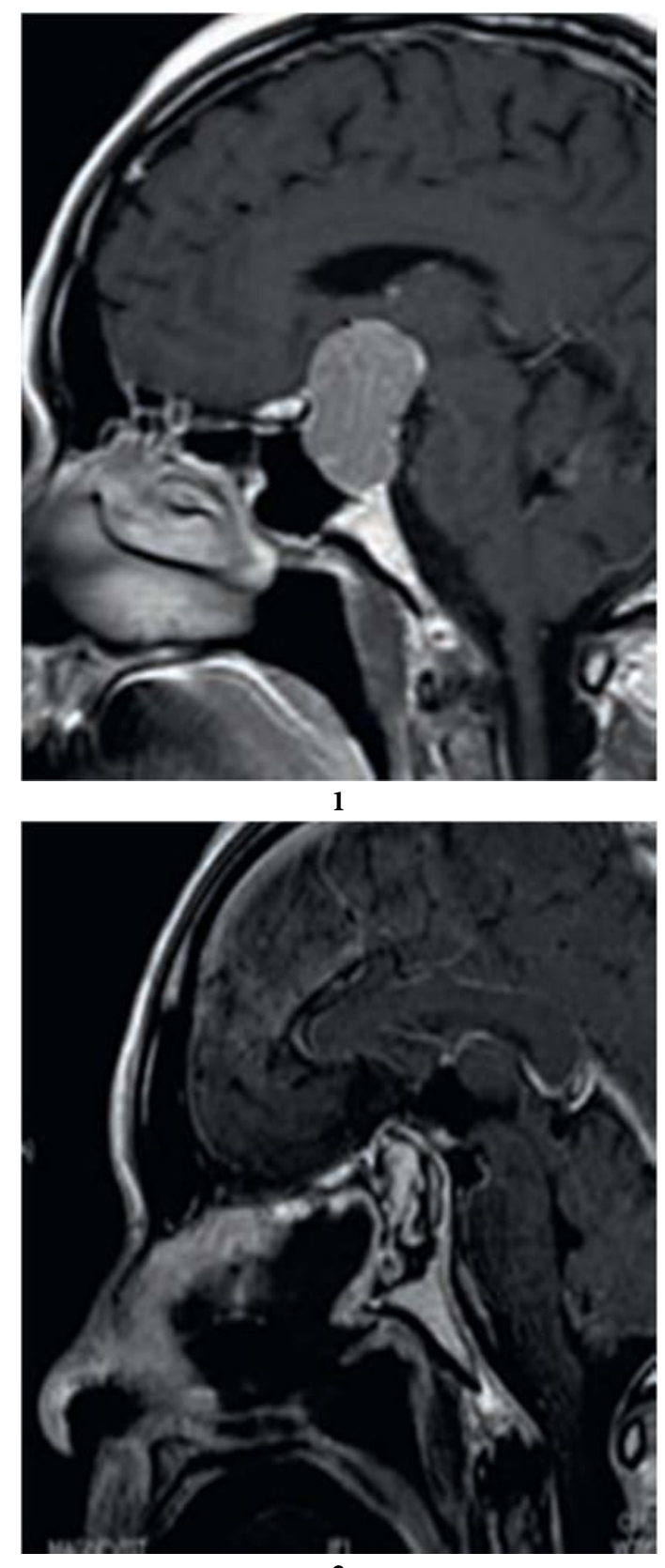


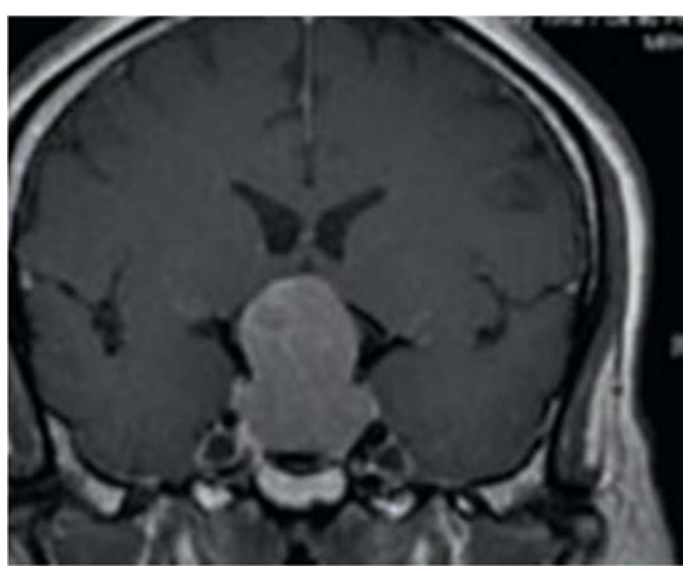

1

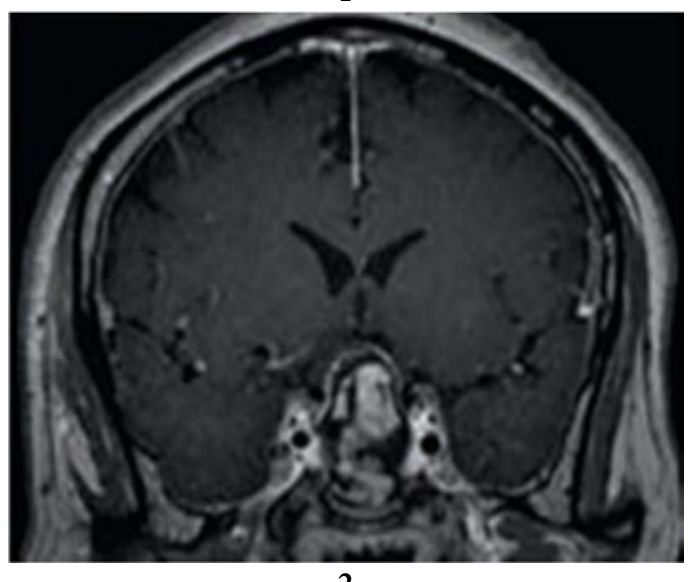

Pre (1) \& Post (2) operative MRI images (Sagittal \& Coronal sections) of endoscopically operated pituitary macroadenoma

Intraoperative blood loss amounting to $<100 \mathrm{ml}$ was noted in twenty five $(83 \%)$ patients of group A while blood loss of $>100$ $\mathrm{ml}$ was seen in twenty five (83\%) patients of group $B$. the $p$ value comes out to be less than 0.001 . The major reason behind this difference could be attributed to the prolonged surgery in group B patients.

Another major complication, i.e. CSF leak was seen in six (20\%) case in group A while in four (13.3\%) cases in group B.

Maximum patients in group A, i.e. twenty (66.67\%) had residual tumor volume of less than $0.5 \mathrm{ml}$ while only three (10\%) patients in group B had so. Eighteen (60\%) patients in group B had a residual volume between 1-1.5 $\mathrm{ml}$ while only two patients in group A had so. This difference is also significant Fischer Exact test $(\mathrm{p}<0.001)$.

As we can see from this table, four (13.3\%) patients in group A had diabites insipidus while only half of this, i.e. two (6.6\%) had so in group B. Postoperative CSF rhinorrhea was seen in an equal number of patients (10\%). Sinusitis was more common in group B (10\% vs $3 \%)$.Vision loss was present in two (6.67\%) cases in group B while none in group A. however this difference in postoperative complication rate is not statistically significant between two groups.

Pituitary tumors are most commonly approached through the transsphenoidal corridor, and tumor resection is most often performed using the operating microscope. More recently the endoscope has been introduced for use either as an adjunct to or in lieu of the microscope. Almost from the outset, the transsphenoidal approach has been minimally invasive. The earliest transsphenoidal surgeries (1907-1909) by Schloffer, van elsberg [26], required external rhinotomy incisions. Endonasal and sublabial approaches were introduced in 1910 by Hirsch and Halstead [14], respectively.

Image guidance in pituitary surgery began with the use of intraoperative air encephalography and c-arm video fluoroscopy, and continues to expand with the 
addition of newer techniques such as intraoperative ultrasound, computer-based neuronavigation, intraoperative MRI, and endoscopic assisted surgery [16-20].

Jankowski et al. [15] were the first to bring their application to access of the pituitary in 1992. endoscopic transsphenoidal approach was popularized in the late 1990s by Jho and Carrau [16] from the University of Pittsburgh Medical Center. Advances in endoscopic endonasal neurosurgical techniques at Pittsburgh continue in the work of Kassam, et al. [21], and Carrau [17], who have expanded the scope of complex skull base tumors accessible by the endoscope. In Europe the neurosurgical groups of Cappabianca and de Divitiis [8] and Frank, et al. [11], have also made important contributions in heralding a new era in contemporary endoscopic pituitary surgery. Several authors have discussed the potential outcome of the endoscopic technique. DeKlotz et al.[9] used a metaanalysis to reveal the superior rate of GTR (79\% versus $65 \%, \mathrm{P}<0.0001)$ as well as the lower rates of CSF leak (5\% versus $7 \%$, $\mathrm{P}<0.01)$, septal perforation ( $0 \%$ versus $5 \%)$ and post-operative epistaxis ( $1 \%$ versus $4 \%$, $\mathrm{P}<0.0001$ ) for the endoscopic approach compared with the sublabial approach. Rotenberg et al. [25] concluded that the two approaches had similar outcomes (GTR, hormonal abnormality resolution) but that the endoscopic approach was associated with fewer complications as well as a shorter hospital stay and length of operation. Goudakos et al. [12] demonstrated that the rates of GTR/CSF leakage were similar between the two techniques. However, the study also revealed a lower incidence of postoperative DI and a shorter hospital stay in the studied endoscopic groups. Other systematic reviews also support the safety and short-term efficacy of endoscopic pituitary surgery $[4,16]$. Interestingly, Ammirati et al. [2] recently reported a meta-analysis concluding that endoscopic removal of pituitary adenoma, in the short term, does not seem to confer any advantage over the microscopic technique and the incidence of vascular complication was higher with endoscopic than with microscopic removal of pituitary adenomas.

The current study compared the endonasal endoscopic and neuronavigation guided microscopic transsphenoidal pituitary surgery for pituitary tumors. In this study we compared tumor remission, intraoperative and immediate postoperative complications among the most widely used methods of endoscopic and neuronavigation assisted microscopic transsphenoidal pituitary surgery. All patients in both groups underwent transsphenoidal removal of pituitary adenomas, using identical surgical techniques with an operating microscope.

In our study, we had 30 patients in group $A$ (endoscopic) and 30 patients in group B (navigation guided microscopic). Both these groups had a similar distribution of patients according to age, sex, tumor volume, tumor spread and their clinical presentation. So all these above mentioned criteria presented no confounding factors in our study. Outcomes of transsphenoidal pituitary surgery were measured along several parameters, first and foremost of which were complications related to surgery. Mortality rates of transsphenoidal 
surgeries are low, generally occurring at a rate of less than $1 \%[22,23,6,7]$. There was no mortality in our study.

The first significant difference noted in our study was the average duration of surgery from incision to closure in both the techniques. The total operating room time includes the time required for the initial set up of the navigation machine and tracer registration along with the actual surgical time (incision to closure). The average time required for surgery was 3-4 hrs in the neuronavigation group. The total operating time in endoscopic group was initially about 4-5 hours, later it was 2-3 hours as the endoscopic expertise increased. The complications heralded by the prolonged surgery are thus obvious. It leads to increased morbidity due to prolonged exposure to anesthesia, \& more blood loss.

The shortened duration of procedure in group $\mathrm{A}$ is due to the easy and accurate localization of the sella turcica and sphenoid sinus which facilitates tumor removal. The surgical time for only four patients in group A was more than 3 hours. The initial three cases in which initial lack of endoscopic skill and intra operative bleeding increased surgical time. In group B intra operative CT registration and neuronavigation, and use of microscope increased the operative time significantly. The time-effectiveness of intraoperative CT registration and electromagnetic neuronavigation in transsphenoidal pituitary surgery was also assessed by Eboly, Shafa et al. They concluded that the use of iCT/MR imaging-guided neuronavigation for microscopic transsphenoidal surgery is a time-effective, cost-efficient, safe, and technically beneficial technique [10].

In our study increased incidence of CSF leak seen in group A could be the result of overenthusiastic resection for tumor removal because of better visualization. This should be discouraged. With an incidence of postoperative CSF leak of $20 \%$ our endoscopic series shows slightly higher CSF leak as most of which occurred during initial few endoscopic procedures. Other systematic review by Rotenberg [1] found a mean incidence of $14.3 \%$ and the meta-analysis of Ammirati [2], evaluated it to be 7.0\% (4.84 to $9.52 \%)$.

In our study there was a significant difference noted in the amount of intraoperative blood loss as estimated by the amount collected in suction bottle.

In our study there was a significant difference noted in the amount of intraoperative blood loss as estimated by the amount collected in suction bottle. This significant difference however was not due to any major hemorrhage which took place during surgery rather it was seen due to the continuous oozing of blood from the mucous membrane during the procedure which is more with the endoscopic surgery. Patel, Youssef et al concluded that computer guided endonasal transsphenoidal surgery provides a three-dimensional image to the surgeon, allowing for greater visual accuracy and surgical precision and a faster procedure without radiation exposure or the need for additional personnel $[24,28]$.

We determined the presence and volume of residual tumor by a CT scan postoperatively. The residual tumor volume in 
$66.6 \%$ patients of group A was $0-0.5 \mathrm{ml}$ while it was $1-1.5 \mathrm{ml}$ in $60 \%$ of patients in group B. None of the group A cases had residual tumor volume more than $1.5 \mathrm{ml}$ while five patients in group B had so We believe these improved outcomes are the result of superior illumination, visualization and angled view provided by the endoscope.

We followed the patients in our study during their postoperative hospital stay and further on follow-up after two weeks. The significant difference in the postoperative complication rate further stresses upon the need of increased accuracy of tumor removal and minimal damage to the nearby structures during surgery.

The accuracy of a surgeon's localization of sellar margins during transsphenoidal surgery for pituitary adenomas using a neuronavigational system was also studied by Wang and Thiryayi et al in 2011 and they established that the margin of error increases for giant adenomas, with greater invasiveness and parasellar spread, and the use of neuronavigation can be especially useful in such cases [27]. Clinical application of a neuronavigation system in transsphenoidal surgery of pituitary macroadenoma was also studied by Zhao, Yu et al in $2006[30,31]$ and found that the neuronavigation system is quite helpful for transsphenoidal surgery of pituitary macroadenoma. Its accuracy of location is very useful and important in determining anatomical structure and protecting normal tissues and vessels.

\section{Conclusion}

The results of our study correlate with many previous studies to compare endoscopic and microscopic transsphenoidal surgery. We have focused solely on transsphenoidal pituitary surgery though some previous researchers have advocated the use of CT/MRI based neuronavigation in variety of other neurosurgical procedures also as also the use of endoscope in skull base surgery. The panoramic view afforded by the endoscope is unparalleled as compared with the traditional conical view of the microscope. This technique has been shown to have a statistically significant reduction in operative time, length of hospital stay. There is also a trend toward improved endocrine outcomes and rate of return of visual defects. These two approaches are equally efficacious in oncological outcomes and the complication rates are comparable. With longer follow-up of this developing field it may be shown that complication rates are decreased, surgical reconstruction is less time consuming, and tumor resection is more complete due to improved visualization in the sellar and parasellar areas. In addition, the use of endoscopes facilitates extended approaches, reaching a myriad of skull base lesions that are suprasellar, retrosellar, and parasellar, which permits visualization beyond the abilities of the microscope.

\section{Correspondence}

Sharad Pandey

Department of Neurosurgery, P.G.I.M.E.R. DR

RAM MANOHAR LOHIA HOSPITAL, New Delhi

110001, India

drsharad23@yahoo.com

Mobile no: 9454939067 


\section{References}

1. Ahmadi H, Larsson EM, Jinkins JR: Normal pituitary gland: Coronal MR imaging of infundibular tilt. Radiology 177:389-392, 1990.

2. Ammirati M, Wei L, Ciric I: Short-term outcome of endoscopic versus microscopic pituitary adenoma surgery: a systematic review and meta-analysis. J Neurol Neurosurg Psychiatry 2013, 84:843-849.

3. Black PM, Zervas NT, Candia GL. Incidence and management of complications of transsphenoidal operation for pituitary adenomas. Neurosurgery. 1987 Jun;20(6):920-4

4. Cappabianca P, Cavallo LM, de Divitiis E. Endoscopic endonasal transsphenoidal surgery. Neurosurgery 2004; 55:933-941.

5. Carrau RL, Jho HD, Ko Y. Transnasal-transsphenoidal endoscopic surgery of the pituitary gland. Laryngoscope 1996;106:914-918.

6. Ciric I, Ragin A, Baumgartner C, Pierce D. Complications of transsphenoidal sur $\neg$ gery: results of a national survey, review of the literature, and personal experience. Neurosurgery. 1997 Feb;40(2):225-36.

7. Cooke RS, Jones RAC. Experience with the direct transnasal transsphenoidal approach to the pituitary fossa. Br J Neurosurg 1994;8:193-196.

8. De Divitiis E, Cavallo LM, Cappabianca P, Esposito F. Extended endoscopic endonasal transsphenoidal approach for the removal of suprasellar tumors: part 2 . Neurosurgery 2007; 60:46-58.

9. De Klotz TR, Chia SH, Lu W, Makambi KH, Aulisi E, Deeb Z: Meta-analysis of endoscopic versus sublabial pituitary surgery. Laryngoscope 2012, 122:511-518.

10. Eboli P, Shafa B, Mayberg M. Intraoperative computed tomography registration and electromagnetic neuronavigation for transsphenoidal pituitary surgery: accuracy and time effectiveness. J Neurosurg. Feb;114(2):329-35, 2011.

11. Frank G, Pasquini E, Doglietto F, et al. The endoscopic extended transsphenoidal approach for craniopharyngiomas. Neurosurgery 2006; 59:ONS75ONS83.

12. Goudakos JK, Markou KD, Georgalas C: Endoscopic versus microscopic transsphenoidal pituitary surgery: a systematic review and meta-analysis. Clin Otolaryngol 2011, 36:212-220.
13. Hardy J. Transphenoidal microsurgery of the normal and pathological pituitary. Clin Neurosurg. 1969;16:185217.

14. Hirsch O: Pituitary tumors. A borderland between cranial and trans-sphenoidal surgery. N Engl J Med 254: 937-939, 1956.

15. Jankowski R, Auque J. Simon C, et al: Endoscopic pituitary tumor surgery. Laryngoscope 102:198-202, 1992.

16. Jho HD, Carrau RL Endoscopic endonasal transsphenoidal surgery: Experience with 50 patients. J Neurosurg 87:44-51, 1997.

17. Jho HD, Carrau RL Ko Y: Endoscopic pituitary surgery. In Rengachary SS, Wilkins RH (eds): Neurosurgical Operative Atlas, vol 5. Baltimore, Williams \& Wilkins, 1996, pp 1-12.

18. Jho HD, Carrau RL, Ko Y, Daly M. Endoscopic pituitary surgery: An early experience. Surg Neurol 1997;47:213-223.

19. Jho HD, Carrau RL, Mclaughlin ML, Somaza SC. Endoscopic transsphenoidal resection of a large chordoma in the posterior fossa. Acta Neurochir (Wien) 1997;139: 343-348.

20. Jho HD, Carrau RL. Endoscopic endonasal transsphenoidal surgery: Experience with 50 patients. J Neurosurg 1997;87: 44-51.

21. Kassam A, Horowitz M, Welch W, et al. The role of endoscopic assisted microneurosurgery (image fusion technology) in the performance of neurosurgical procedures. Minim Invasive Neurosurg 2005; 48:191196.

22. Laws ER Jr, Sheehan JP (eds): Pituitary Surgery - A Modern Approach. Front Horm Res. Basel, Karger, , vol 34, pp 46-63, 2006.

23. Laws ER Jr. Pituitary surgery. Endocrinol Metab Clin North Am 16:647-665, 1987.

24. Patel SN, Youssef AS, Vale FL, Padhya TA. Reevaluation of the role of image guidance in minimally invasive pituitary surgery: benefits and outcomes. Comput Aided Surg.; 16 (2):47-53, 2011.

25. Rotenberg B, Tam S, Ryu WH, Duggal N: Microscopic versus endoscopic pituitary surgery: a systematic review. Laryngoscope 2010, 120:1292-1297.

26. Schloffer H. Erfulgrieche operation hypophys ent tumors on nasal wege. Wien Klin Wochenschr 1907; 20:621-624. 
27. Wang YY, Thiryayi WA, Ramaswamy R, Gnanalingham KK. Accuracy of Surgeon's Estimation of Sella Margins during Endoscopic Surgery for Pituitary Adenomas: Verification Using Neuronavigation. Skull Base. May; 21(3):193-200, 2011.

28. Winder MJ, Spooler A, Mayberg MR. The evolution of intraoperative imaging and neuro-navigation in transsphenoidal surgery. J Surg Radiol. Jan 1;2(1), 2011. 29. Wurster CF, Smith DE: The endoscopic approach to the pituitary gland. Arch Otolaryngol Head Neck Surg 120:674, 1994
30. Zhang Y, Wang Z, Liu Y, et al. Endoscopic transsphenoidal treatment of pituitary adenomas. Neurol Res 2008; 30:581-586.

31. Zhao B, Wei YK, Li GL, et al. Extended ranssphenoidal approach for pituitary adenomas invading the anterior cranial base, cavernous sinus, and clivus: a single-center experience with 126 consecutive cases. J Neurosurg 2010; 112(1):108-117. 